\title{
MAXIMUM PRINCIPLES FOR A CLASS OF LINEAR ELLIPTIC EQUATIONS OF EVEN ORDER
}

\author{
Cristian-PAul DANet And Anita Mareno
}

Abstract. In this paper we define several types of functions on the solution to a class of linear elliptic equations of even order. We establish that these functions satisfy a classical maximum principle. As a consequence we obtain uniqueness results and bounds on various quantities of interest.

Mathematics subject classification (2010): 35B50, 35G15, 35J40.

Keywords and phrases: maximum principles, higher order, elliptic.

\section{REFERENCES}

[1] S. N. Chow, D. R. Dunninger, A maximum principle for n-metaharmonic functions, Proc. Amer. Math. Soc. 43 (1974), 79-83.

[2] C.-P. DANET, Uniqueness results for a class of higher - order boundary value problems, Glasgow Math. J. 48 (2006), 547-552.

[3] C.-P. DANET, On the elliptic inequality L $u \leqslant 0$, Math. Inequal. \& Appl. 11 (2008), 559-562.

[4] C.-P. DANET, Uniqueness in some higher order elliptic boundary value problems in $n$ dimensional domains, E. J. Qualitative Theory of Diff. Eq. 54 (2011), 1-12.

[5] C.-P. DANET, A remark on a uniqueness result for a boundary value problem of eighth-order, Applied E-Notes 9 (2009), 192-196.

[6] D. R. Dunninger, Maximum principles for solutions of some fourth - order elliptic equations, J. Math. Anal. Appl. 37 (1972), 655-658.

[7] S. Goyal AND V. B. Goyal, Liouville -type and uniqueness results for a class of sixth-order elliptic equations, J. Math. Anal. Appl. 139 (1989), 586-599.

[8] A. MaReno, Maximum principles for some higher-order semilinear elliptic equations, Glasgow Math. J. 53 (2010), 313-320.

[9] L. E. PAYNE, Some remarks on maximum principles, J. Analyse Math. 30 (1976), 421-433.

[10] G. A. Philippin, S. Vernier-PIro, Applications of the maximum principle to a variety of problems involving elliptic and parabolic equations, Nonlinear Anal. 47 (2001), 661-679.

[11] M. H. Protter And H. F. Weinberger, Maximum principles in differential equations, PrenticeHall, Inc., Englewood Cliffs, N. J., 1967.

[12] P. W. SCHAEFER, On a maximum principle for a class of fourth - order semiliniar elliptic equations, Proc. Roy. Soc. Edinburgh 77A (1977), 319-323.

[13] P. W. SCHAEFER, Uniqueness in some higher order elliptic boundary value problems, Z. Angew. Math. Phys. 29 (1978), 693-697.

[14] P. W. Schaefer AND W. Walter, On pointwise estimates for metaharmonic functions, J. Math. Anal. Appl. 69 (1979), 171-179.

[15] R. P. SPERB, Maximum principles and their applications, Academic Press, New York, 1981.

[16] S. TsEng AND C.-S. Lin, On a subharmonic functional of some even order elliptic problems, J. Math. Anal. Appl. 207 (1997), 127-157. 